\title{
3D SCAFFOLDS CO-SEEDED WITH HUMAN ENDOTHELIAL PROGENITOR AND MESENCHYMAL STEM CELLS: EVIDENCE OF PREVASCULARISATION WITHIN 7 DAYS
}

F. Duttenhoefer ${ }^{1,2}$, R. Lara de Freitas ${ }^{1,3}$, T. Meury ${ }^{1,4}$, M. Loibl ${ }^{1,5}$, L.M. Benneker ${ }^{6}$, M. Herrmann ${ }^{1}$, R.G. Richards ${ }^{1}$, M. Alini ${ }^{1}$ and S. Verrier ${ }^{1, *}$

${ }^{1}$ AO Research Institute Davos, Davos, Switzerland

${ }^{2}$ Department of Oral and Maxillofacial Surgery, Albert-Ludwigs-University, Freiburg, Germany ${ }^{3}$ Medical School of Ribeirão Preto, University of São Paulo, São Paulo, Brazil

${ }^{4}$ Roche, Basel, Switzerland

${ }^{5}$ Department of Trauma Surgery, Regensburg University Medical Centre, Regensburg, Germany ${ }^{6}$ Department of Orthopaedic Surgery, Inselspital, University of Bern, Switzerland

Abstract

Blood supply is a critical issue in most tissue engineering approaches for large defect healing. As vessel ingrowth from surrounding tissues is proven to be insufficient, current strategies are focusing on the neo-vascularisation process.

In the present study, we developed an in vitro prevascularised construct using 3D polyurethane (PU) scaffolds, based on the association of human Endothelial Progenitor Cells (EPC, CD34+ and CD133+) with human Mesenchymal Stem Cells (MSC). We showed the formation of luminal tubular structures in the co-seeded scaffolds as early as day 7 in culture. These tubular structures were proven positive for endothelial markers von Willebrand Factor and PECAM-1. Of special significance in our constructs is the presence of CD146-positive cells, as a part of the neovasculature scaffolding. These cells, coming from the mesenchymal stem cells population (MSC or EPC-depleted MSC), also expressed other markers of pericyte cells (NG2 and $\alpha \mathrm{SMA}$ ) that are known to play a pivotal function in the stabilisation of newly formed prevascular networks. In parallel, in co-cultures, osteogenic differentiation of MSCs occurred earlier when compared to MSCs monocultures, suggesting the close cooperation between the two cell populations. The presence of angiogenic factors (from autologous platelet lysates) in association with osteogenic factors seems to be crucial for both cell populations' cooperation. These results are promising for future clinical applications, as all components (cells, growth factors) can be prepared in an autologous way.

Keywords: Mesenchymal stem cells; endothelial progenitor cells; bone; neovascularisation; 3D; co-cultures; autologous; platelet lysates.

\footnotetext{
*Address for correspondence:

Sophie Verrier

AO Research Institute

Clavadelerstrasse 8

CH-7270 Davos, Switzerland

Telephone Number: +41814142448

FAX Number: +41814142288

Email: sophie.verrier@aofoundation.org
}

\section{Introduction}

Bone is a highly vascularised tissue that generally leads to spontaneous regeneration of shape and function without scar formation (Salgado et al., 2004). During bone remodelling and repair, new capillaries derived from pre-existing neighbour vessels invade the site through angiogenesis (Carano and Filvaroff, 2003). Thus, the best healing rates of injuries occur mainly in areas with the highest level of vascularisation (Deleu and Trueta, 1965; Novosel et al., 2011).

In cases of large bone defects, not only is the bone tissue damaged, but the surrounding vasculature is often notably debilitated, impairing adequate levels of oxygen and nutrient supply at the injury site and ultimately proper healing (Rhinelander, 1965; Johnson et al., 2011). With a growth rate of around $5 \mu \mathrm{m} / \mathrm{h}$, sprouting-out from existing vessels is limited in space, and a time-consuming process that requires the presence of blood vessels in the immediate surroundings (Laschke and Menger, 2012).

Bone repair highly depends on the presence of osteogenic cells at the healing site (Mandracchia et al., 2001; Carano and Filvaroff, 2003), and bone marrow is a natural reservoir of skeletal stem cells. Recruitment, proliferation and differentiation of MSCs into mature osteoblasts are regulated by many factors including cytokines, growth factors and systemic hormones. These factors are released not only by osteoblastic cells themselves (Lian and Stein, 1995), but also by cells that are part of the tightly connected vascular system, such as endothelial cells (Wang et al., 1997; Street et al., 2002; Villars et al., 2002; Fuchs et al., 2007) and pericytes (Jones et al., 1995).

Many studies underline the close relationship between angiogenesis and ontogenesis. Cross-talk between endothelial cells and osteoblasts has been reported, through secreted factors (e.g., VEGF) and through direct cell-cell interactions (e.g., cell surface proteins, gap junctions) (Villars et al., 2000; Meury et al., 2006; Grellier et al., 2009; Santos et al., 2009). Based on this knowledge, contemporary advances focus on neovascularisation of tissue-engineered bone implants (Rafii and Lyden, 2003; Unger et al., 2007; Hofmann et al., 2008; Laschke et al., 2008; Fuchs et al., 2009; Capobianco et al., 2010). Postnatal neovascularisation is thought to exclusively result from proliferation, migration, and remodelling of fully differentiated endothelial cells (EC) sprouting from 
existing vessels (angiogenesis). In contrast, vasculogenesis, which occurs during embryo development, involves blood vessel formation from endothelial progenitor cells (EPC), also called angioblasts. Recent cumulative evidence indicates that peripheral blood of adults contains bonemarrow derived progenitor EPCs with properties similar to those of embryonic angioblasts (Asahara et al., 1997; Gehling et al., 2000; Hristov et al., 2003; Hristov and Weber, 2004; Zammaretti and Zisch, 2005). A fundamental advantage of EPCs is that they can be isolated from the patient's own blood and bone marrow.

The aim of the present study was to develop a prevascularised bone implant that would enable a faster blood supply throughout implanted tissue-engineered bone constructs. To our knowledge, no study has elucidated the neovascularisation potential of EPCs co-cultured with MSCs in a 3D environment.

Firstly, we examined the ability of EPCs alone, or in association with MSCs, to develop mature endothelial cell properties in a 2D cell culture environment. Secondly, these two cell populations were cultured on their own, or in association within a polyurethane 3D scaffold. Several cell-culture conditions were tested, including autologous Platelet Rich Plasma (PRP) and Platelet Lysate growth factors (PL), in order to establish the optimal condition for both cell types (Lippross et al., 2011).

\section{Materials and Methods}

\section{Cell culture media}

For the co-culture of different cell types (EPC / HUVEC and MSC), different cell culture media compositions were tested. The Iscove Modified Dulbecco's Medium (IMDM), Foetal Calf Serum (FSC), Non-Essential Amino Acids (NEAA) and antibiotics (PenStrep, PS) were all from Gibco/Invitrogen Life Technologies (Zug, Switzerland). The Basic Fibroblast Growth Factor (bFGF) was from R\&D Biosystems (Minneapolis, MN, USA). Ascorbic acid, $\beta$-glycerophosphate and dexamethasone were all from Sigma-Aldrich (Hamburg, Germany). M200 plus Low Serum Growth Supplement (LSGS) was purchased from Cascade Biologics (Portland, OR, USA).

Medium 1: IMDM-5 \% FCS-5 \% PL growth factors Medium 2: M200-LSGS

Medium 3: $50 \%$ Medium $1+50 \%$ osteogenic medium (IMDM-10\% FCS-10 nM dexamethasone - $10 \mathrm{mM}$ $\beta$-glycerophosphate $-0.1 \mathrm{mM}$ Ascorbic acid)

Medium 4: $50 \%$ Medium 2+ $50 \%$ osteogenic medium.

\section{PL and PRP preparation}

Platelet Lysate growth factors (PL) and Platelet Rich Plasma (PRP) were prepared from platelet concentrates, as described earlier (Verrier et al., 2010; Lippross et al., 2011). Platelet bags were obtained from the blood bank of Kantonspital Graubünden in Chur (Switzerland) in accordance with the current ethical laws of Switzerland. The platelet bags contain a standardised platelet density (5 times higher than normal), obtained through blood apheresis. We further increased the platelet density
Table 1. PRP/PL protein content. PDGF-AB, PDGF$\mathrm{BB}$, and VEGF concentration in several PL and PRP preparations were quantified by ELISA. The results are presented in $\mathrm{ng} / \mathrm{mL} \pm$ standard deviation. No major differences could be observed between samples from different donors, or different pools (mixes of 3 donors).

\begin{tabular}{|c|c|c|c|}
\cline { 2 - 4 } \multicolumn{1}{c|}{} & PDGF-AB & PDGF-BB & VEGF \\
\hline $\begin{array}{c}\text { PL } \\
\text { Samples }\end{array}$ & $\begin{array}{c}\mathrm{ng} / \mathrm{mL} \\
\pm \mathrm{sd}\end{array}$ & $\begin{array}{c}\mathrm{ng} / \mathrm{mL} \\
\pm \mathrm{sd}\end{array}$ & $\begin{array}{c}\mathrm{ng} / \mathrm{mL} \\
\pm \mathrm{sd}\end{array}$ \\
\hline \multirow{2}{*}{ Mix 1 } & 7.570 & 5.677 & 0.567 \\
& \pm 1.772 & \pm 0.848 & $\pm \mathrm{na}$ \\
\hline \multirow{2}{*}{ Mix 2 } & 67.491 & 7.359 & 1.517 \\
& \pm 10.321 & \pm 1.216 & \pm 0.323 \\
\hline \multirow{2}{*}{ Mix 3 } & 26.436 & 4.674 & 0.761 \\
& \pm 2.404 & \pm 0.958 & \pm na \\
\hline \multirow{2}{*}{ donor 1 } & 46.549 & 9.673 & 1.084 \\
& \pm 3.245 & \pm 0.892 & \pm 0.195 \\
\hline \multirow{2}{*}{ donor 2 } & 63.885 & 11.141 & 1.902 \\
& \pm 10.208 & \pm 1.537 & \pm 0.211 \\
\hline \multirow{2}{*}{ donor 3 } & 28.701 & 4.522 & 1.299 \\
& \pm 2.718 & \pm 0.310 & \pm 0.211 \\
\hline
\end{tabular}

PRP: Platelet Rich Plasma, PL: Platelet Lysate, PDGF: Platelet Derived Growth Factor, VEGF: Vascular Endothelial Growth Factor, sd: standard deviation, na: not available.

by a centrifugation at $2000 \mathrm{~g}$ for $7 \mathrm{~min}$, followed by resuspension of the pellet in half of the original plateletbag volume. Phosphate buffered saline (PBS) was used for the PL preparations, while original plasma was used for the PRP preparations, to obtain a final concentration 10 times higher than normal blood (2.5 million $( \pm 10 \%)$ platelets $/ \mu \mathrm{L})$. PL and PRP samples were pooled from three different platelet concentrates and randomly matched. The quality of the samples was tested by ELISA (DuoSet, R\&D Biosystems) dosage of PDGF-AB, PDGF-BB and VEGF on a Perkin Elmer (Waltham, MA, USA) Victor3 Reader 1420-050. As expected, the concentrations we obtained (3 mixes of 3 donors, and 3 individual donors) were about 10 times higher than the range measured in blood plasma (Table 1).

\section{Cell isolation}

Human bone marrow aspirates $(20 \mathrm{~mL})$ were obtained upon informed consent and ethical approval (KEK Bern 126/03) from 5 donors (44 to 83 years old, average age 62 years; 4 males and 1 female) undergoing routine orthopaedic surgery. The samples were collected in CPDA-containing Sarstedt S-Monovettes (Sarstedt, Nümbrecht, Germany) and processed within 12-24 $\mathrm{h}$ after harvesting.

\section{Mesenchymal Stem Cells (MSC)}

MSCs were isolated from bone marrow aspirates by Histopaque-1077 (Sigma-Aldrich) density gradient centrifugation. As previously described (Martin et al., 1997; Meury et al., 2006), bone marrow was homogenised and diluted 1:4 with IMDM containing $5 \%$ FCS. After slowly pipetting onto the Histopaque, the samples 
were centrifuged at $800 \mathrm{~g}$ for $20 \mathrm{~min}$. The low-density mononucleated cell interphase was collected and washed twice in $5 \mathrm{~mL}$ of IMDM $10 \% \mathrm{FCS}$, followed by $15 \mathrm{~min}$ centrifugation at $400 \mathrm{~g}$.

\section{Endothelial Progenitor Cells (EPC)}

EPCs (CD34+/CD133+) were further selected from the previously isolated MSCs using magnetic microbeads linked to antibodies specific to CD34 (MACS system, Miltenyi Biotec, Bergisch Gladbach, Germany), according to the manufacturer's instructions. To confirm their EPC phenotype, the selected cells were characterised by FACS analysis (BD FACS AriaIII, BD Biosciences, Allschwil, Switzerland) using CD34, CD133 and CD309 specific antibodies (Miltenyi Biotec) and their ability to incorporate Dil AcLDL (Invitrogen, Basel, Switzerland). The EPCdepleted population was called minus-minus (MM).

\section{Human Umbilical Vein Endothelial Cells (HUVEC)}

HUVECs (Cascade Biologics) were used as an endothelial cell positive control.

\section{Cell amplification}

Cells were counted using a haemocytometer chamber under a bright field microscope, seeded at the initial density of 10,000 cells $/ \mathrm{cm}^{2}$ in cell culture flasks (Techno Plastic Products, Trasadingen, Switzerland) and cultured in the appropriate cell culture medium as follows:

- MSCs and MM cells were amplified in IMDM, containing PenStrep (100 U/ml), $10 \%$ FCS, $1 \%$ NEAA and $5 \mathrm{ng} / \mathrm{mL}$ bFGF.

- EPCs were cultured in Medium 1.

- HUVECs were cultured in Medium 2.

All cell types were cultured at $37{ }^{\circ} \mathrm{C}$ in a $5 \% \mathrm{CO}_{2}$ humidified atmosphere incubator, with the media changed twice a week. Cells between passages 2 and 4 were subsequently used.

\section{Cell co-cultures}

2D Matrigel ${ }^{T M}$ tube formation assay

Cell culture wells $\left(3.6 \mathrm{~cm}^{2}\right)$ were coated with $50 \mu \mathrm{L} / \mathrm{cm}^{2}$ of Growth Factor reduced Matrigel ${ }^{\mathrm{TM}}$ (BD Biosciences). Prior to seeding, EPCs and HUVECs were labelled using PKH67-green ${ }^{\circledR}$ (Sigma-Aldrich). MSCs and MM cells were labelled using PKH26-red ${ }^{\circledR}$ (Sigma-Aldrich). HUVECs were used as a positive control for cellular network formation. Ten thousand cells were seeded in each well. Cells were either seeded as a single cell type (one cell type per well) or co-seeded with another cell type in a 50-50 ratio (MSC+HUVEC, MSC+EPC, MM+HUVEC, $\mathrm{MM}+\mathrm{EPC})$. Samples were cultured in Medium 1 for short incubation time, and in Medium 3 for longer time (7 days). Each condition was seeded in triplicate, and was repeated using cells from 3 different donors. Cells were incubated for $1,5,24$ hours and 7 days at $37{ }^{\circ} \mathrm{C}$ in a $5 \% \mathrm{CO}_{2}$ incubator. Samples were then observed by epifluorescence microscopy using an inverted microscope Axiovert 200M with Axiovision software (Carl Zeiss, Jena, Germany).

\section{$3 D$ cell culture}

Bioresorbable elastomeric polyurethane (PU) scaffolds containing nanoparticles of hydroxyapatite (HA) were used throughout all experiments (Gorna and Gogolewski, 2000; Gorna and Gogolewski, 2003; Laschke et al., 2010). The scaffolds represented a volume of $9 \mathrm{~mm}^{3}$ $(1 \mathrm{~mm} \times 3 \mathrm{~mm} \times 3 \mathrm{~mm})$ and an open porosity with a pore size of 200-630 $\mu \mathrm{m}$ (Gorna and Gogolewski, 2006). The scaffolds were seeded with 70,000 cells each in different cell type combinations as described for the Matrigel $^{\mathrm{TM}}$ experiments, but without cell pre-staining. Cells were trypsinised, counted as previously described, and resuspended in PRP ( $3 \mu \mathrm{L} /$ scaffold) in the presence of thrombin $(5 \mathrm{U} / \mathrm{mL}$ final) to promote gelification. These cell/PRP preparations were rapidly soaked into the elastomeric PU scaffolds (sponge effect) enabling a deep and even repartition of the cells within the structure. The cell-seeded scaffolds were cultured in a $37{ }^{\circ} \mathrm{C}$ and $5 \%$ $\mathrm{CO}_{2}$ incubator in the presence of Medium 1, Medium 2, Medium 3 or Medium 4. The scaffolds were seeded and analysed for each condition in duplicate (histology staining, immunostaining, tubular structure quantification), and the whole experiment was repeated with cells from 3 different donors.

\section{Immunostaining \\ $2 D$ co-culture immunocytochemistry}

In order to characterise the cells participating in the cellular network formation, immunostaining was performed using CD146-specific antibodies (Abcam, Cambridge, UK). Matrigel ${ }^{\mathrm{TM}}$ samples were fixed for $10 \mathrm{~min}$ in PBS containing $5 \%$ glutaraldehyde (Agar Scientific, Stansted, UK) then rinsed for $10 \mathrm{~min}$ in distilled water. After washing for $5 \mathrm{~min}$ in PBS and blocking non-specific binding sites by incubating $1 \mathrm{~h}$ in a 1:20 goat serum solution, samples were incubated for $30 \mathrm{~min}$ in the CD146-specific antibody, diluted 1:1000. After 3 washing steps for 5 min each in PBS-Tween, the secondary antibody fluorescent blue Alexa Fluor 350 (Invitrogen/Life Technologies) was added in a 1:200 dilution and incubated for $30 \mathrm{~min}$. Samples were then washed for $5 \mathrm{~min}$ in PBS-Tween, and were viewed microscopically while in PBS.

\section{$3 D$ co-cultures immunohistochemistry}

After 7 days, the scaffolds were transferred into wells containing "Tissue freezing media" (Leica Microsystems, Nussloch, Germany) for cryosectioning. After snapfreezing in isopentane (Sigma-Aldrich) cooled in liquid nitrogen, the frozen scaffolds were sectioned $(10 \mu \mathrm{m})$ using a Microm HM 560 microtome (Thermo Scientific, Walldorf, Germany), and collected on Superfrost Plus ${ }^{\circledR}$ microscope slides (Gerhard Menzel, Braunschweig, Germany). Sections were preserved at $-20{ }^{\circ} \mathrm{C}$ until use.

Cryosections were fixed in $70 \%$ methanol for $15 \mathrm{~min}$ and rehydrated in PBS for $10 \mathrm{~min}$. The slides were incubated for $30 \mathrm{~min}$ in methanol containing $0.3 \% \mathrm{H}_{2} \mathrm{O}_{2}$ to block endogenous peroxidase, then transferred to a moist chamber for the staining processes. After blocking nonspecific sites with a $1 \mathrm{~h}$ incubation in horse serum (diluted 1:20 in PBS-Tween, Vector Labs, Burlingame, CA, USA), 
samples were incubated for $30 \mathrm{~min}$ in the primary antibody diluted at the optimal concentration: von Willebrand Factor (vWF)(F8-86, Signet 115-01; Covance, Princeton, NJ, USA) was used at 1:400 and CD146 (Abcam) at 1:1000. aSMA (Abcam), NG2 (Abcam), and PECAM-1 (R\&D Systems) were diluted to a final concentration of $0.5 \mu \mathrm{g} /$ $\mathrm{mL}, 3.85 \mu \mathrm{g} / \mathrm{mL}$, and $1 \mu \mathrm{g} / \mathrm{mL}$, respectively. The primary antibodies were omitted and replaced by PBS-Tween for the negative controls. After 3 washings in PBS-Tween, the secondary antibodies were added and incubated for 30 min. Biotinylated goat anti-rabbit (dilution 1:200, Vector Labs: BA-1000) was used to detect the vWF antibody. A biotinylated horse anti-mouse (Vectastain ABC kit, Vector Labs), at a dilution of 1:200, was used to detect the CD146 and PECAM antibodies. After washing in PBS-Tween, antibodies were visualised with the Vectastain Elite ABC kit and DAB (both Vector Labs). Slides were cover-slipped with Prolong Gold Antifade reagent with DAPI (for nuclear counterstain) (Invitrogen/Molecular Probes). For digital photographic documentation an Axioplan upright microscope with Axiovision software (Carl Zeiss) was used.

\section{Tubular structures quantification}

Tubular structures were quantified by manual counting performed by 2 different observers. Five fields of view were counted per section taken from separate samples ( 2 sections per sample, 2 samples per donor, 3 donors). Results were analysed by one-way analysis of variance (ANOVA) corrected by Bonferoni (SPSS software/IBM, Armonk, NY, USA) $(*: p<0.05, * *: p<0.01)$.

\section{Results}

\section{Cell characterisation}

Total bone marrow mononucleated cells (Histopaque interphases) and EPCs (post Miltenyi magnetic microbeads isolation) from 5 donors were characterised by FACS analyses (Table 2) . After Histopaque isolation, about $6 \%$ of the total cells were CD34+, from which $0.4 \%$ were CD34/CD133 positive. After the EPCs' enrichment, around $11 \%$ of the CD34+ cell population was also CD133+. The number of triple positive cells (CD34+/CD133+/CD309+) was quite low, which can be explained by the fact that the post-enrichment cell populations were analysed at later passages ( $>$ p4). However, around $75 \%$ of the cells were able to incorporate Dil acLDL.

\section{Matrigel $^{\mathrm{TM}}$ tubular structure assay}

After amplification in the corresponding cell growth media, the different cell types were seeded on reduced growth factor Matrigel ${ }^{\mathrm{TM}}$ either on their own (HUVEC, MSC, EPC, MM) or in association with another cell type (MSC/HUVEC, MSC/EPC, MM/HUVEC, MM/EPC), and incubated for different periods of time at $37^{\circ} \mathrm{C}$ and $5 \% \mathrm{CO}_{2}$ with Medium 1. After $4 \mathrm{~h}$ HUVECs migrated towards each other and started to establish cell-cell interactions (Fig. 1a) that got more structured after longer incubation times (Fig. 1b). We could detect a similar network formation in EPCs cultures. Already after $4 \mathrm{~h}$ in culture, EPCs formed a cellular network (Fig. 1c) that became more structured after $24 \mathrm{~h}$ (Fig. 1d). At the same observation time points, MSCs alone or the MM cell fraction (Figs. 1e-g) only adhered and started to present cytoplasmic extensions. At 24 hours, some cells in the MSC cultures (Fig. 1f) also started to organise a cellular network, while MM cells never showed such structures (Fig. 1h).

When EPCs were added to the MSCs or to the MM cell populations (in presence of Medium 1), a rapid (already after 5 h, Figs. 2a-b) and complex cellular network could be observed involving both EPCs (stained in green) and some cells (but not all) from the MSC or MM populations (stained in red). This cellular network became more organised over time (Figs. 2c-d), forming tubular-like structures (representative pictures of 3 donors). In order to investigate the nature of the cells from the MSC or MM populations that were enrolled in the cellular network, we performed some immunostaining using a CD146specific antibody at different time points of co-culture on Matrigel $^{\mathrm{TM}}$ (5 h, $24 \mathrm{~h}$ and 7 days). After 5 and $24 \mathrm{~h}$, no CD146 staining could be observed. However, after 7 days (Fig. 3) some cells showed a positive signal for CD146. Fig. 3a (phase contrast microscopy) shows the aspect of the EPC/MSC co-culture after 7 days incubation in Medium 3. In contrast to the previous Matrigel ${ }^{\mathrm{TM}}$ results (Fig. 2) where the cells had a "3-dimensional" shape, after 7 days the cells grew much more and adopted a more flattened

Table 2. FACS characterisation of full bone marrow mononucleated cell population and EPC enriched population. Samples were analysed directly after histopaque density gradient and percentages of CD34+, CD133+, and CD309+ single or double positive populations were established. The same was performed after EPC enrichment through the Miltenyi microbeads system (CD34+). Samples from 5 different donors were tested, and results are presented as percentage of the tested population \pm standard deviation. $(\mathrm{nd}=$ not detected $)$.

\begin{tabular}{|c|c|c|}
\cline { 2 - 3 } \multicolumn{1}{c|}{} & Bone marrow populations & post EPC enrichment \\
\hline CD34+ & $6.2 \pm 3.9 \%$ & $73.5 \pm 24.3 \%$ \\
\hline CD34+/CD133+ & $0.46 \pm 0.37 \%$ & $10.9 \pm 15 \%$ \\
\hline CD133+ & $0.3 \pm 0.26 \%$ & $\mathrm{nd}$ \\
\hline CD309+ & $0.2 \pm 0.14 \%$ & $0.15 \pm 0.07 \%$ \\
\hline CD34+/CD309+ & $\mathrm{nd}$ & $0.15 \pm 0.07 \%$ \\
\hline Lectin uptake & $1 \%$ & $45.2 \%$ \\
\hline
\end{tabular}



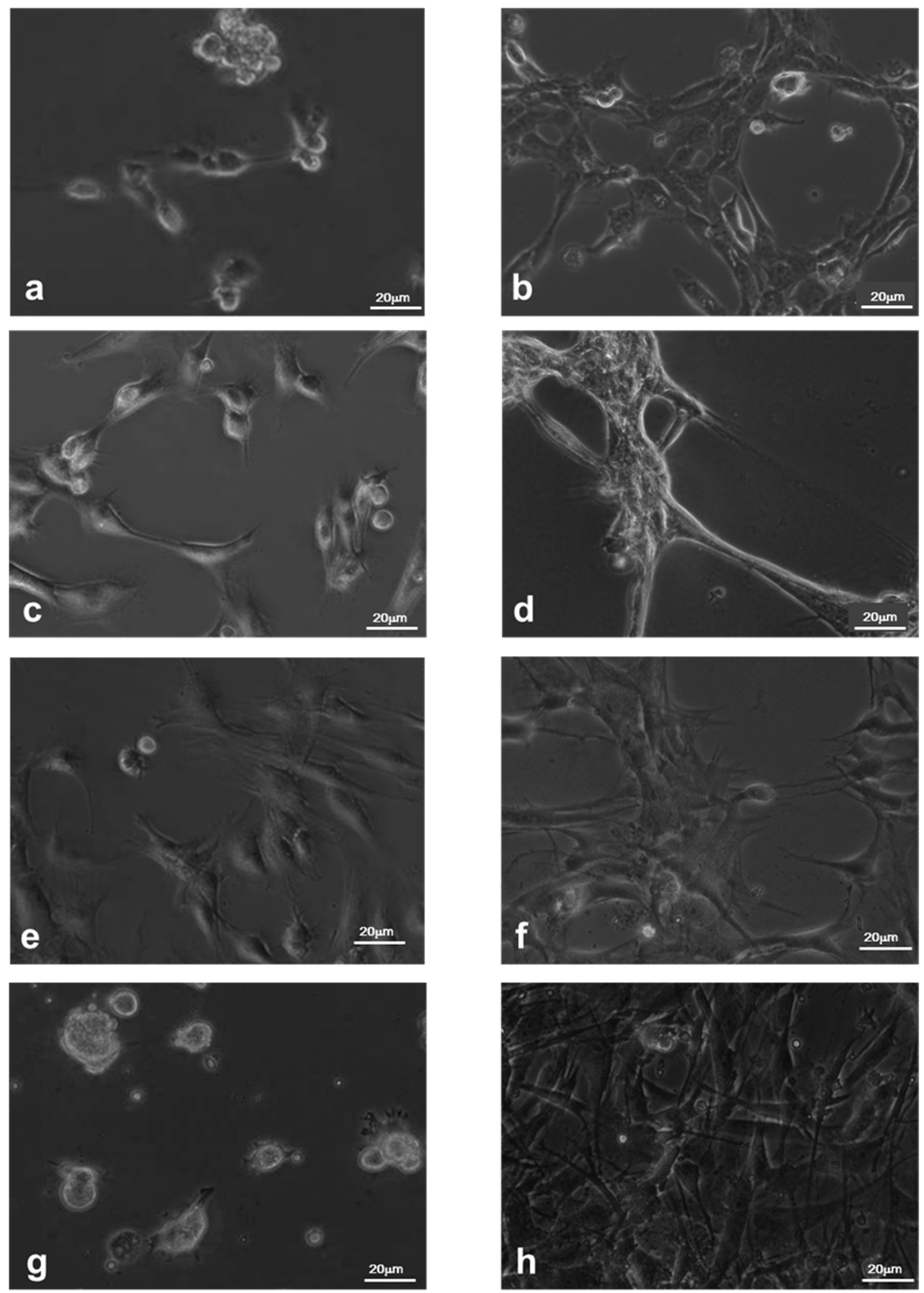

Fig. 1. Tube formation capacity of the different cell types on Matrigel ${ }^{\mathrm{TM}}$ assays. Images are representative pictures from wells seeded in triplicate using cells from 3 different donors. After cell amplification in Medium 2 (HUVEC, a-b), Medium 1 (EPC, c-d) or IMDM $10 \%$ FCS (MSC, e-f and MM, g-h), each population was seeded on a thin layer of Matrigel ${ }^{\mathrm{TM}}$ in the presence of Medium 1. Pictures were taken using contrast phase microscopy after $4 \mathrm{~h}$ (a, $\mathbf{c}, \mathbf{e}, \mathbf{g})$ and $24 \mathrm{~h}(\mathbf{b}, \mathbf{d}, \mathrm{f}, \mathbf{h})$ incubation in a $37^{\circ} \mathrm{C}$ and $5 \% \mathrm{CO}_{2}$ incubator. After $4 \mathrm{~h}, \mathrm{HUVECs}$, EPCs started to form a cellular network $(\mathbf{a}, \mathbf{c})$ increasing afterwards $(\mathbf{d}, \mathbf{e})$, while no such organised cell interaction was observed with $\operatorname{MSCs}(\mathbf{e}, \mathbf{f})$ or MM population $(\mathbf{g}, \mathbf{h})$. 

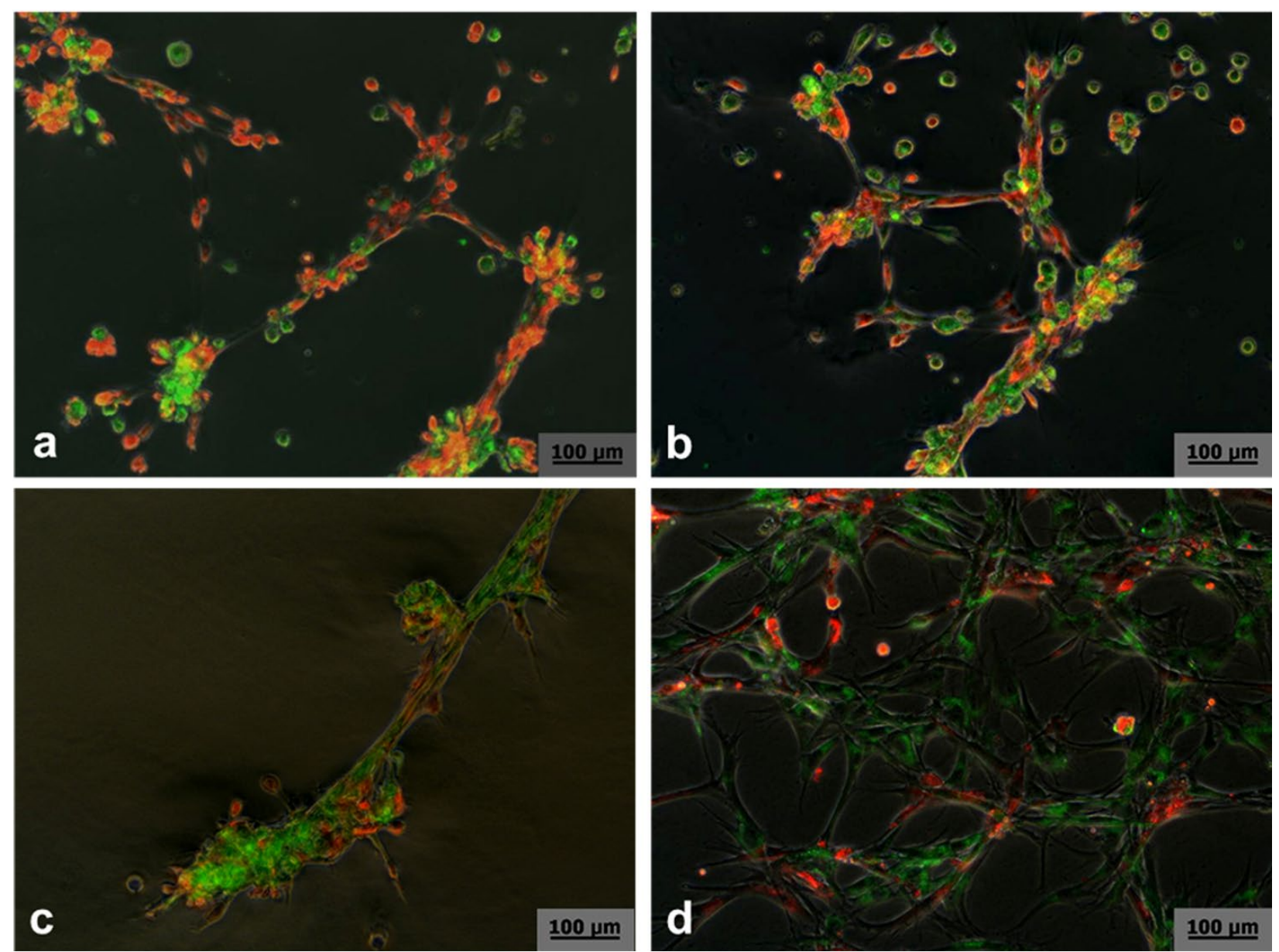

Fig. 2. Mesenchymal stem cells participate in the formation of a tubular network. Cells from 3 donors were seeded on

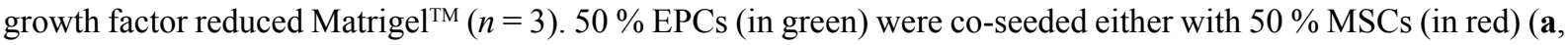
c) or with $50 \% \mathrm{MMs}$ (in red) (b, d). Cells were incubated for $4 \mathrm{~h}(\mathbf{a}, \mathbf{b})$ or $24 \mathrm{~h}(\mathbf{c}, \mathbf{d})$ in the presence of Medium 1, and observed with epifluorescence microscopy. After $4 \mathrm{~h}$, both co-cultures exhibit an early cellular network formation with both cell types participating (a, c). After $24 \mathrm{~h}$, more complex cellular/tubular networks are produced (b, d).

appearance on most of the surface. Only a few places still showed "3-dimensional" cells, and when observed under fluorescent microscopy, the pre-stained EPCs appeared green (Figs. 3b-d) while the MSCs appeared red (Figs. 3c-d). CD146 staining was only observed in the "3-dimensional" cell areas. No staining was observed in the surrounding flattened cells, due to the fact that the pre-staining dyes (PKH67 and PKH26) fade upon cell proliferation. On the merged picture of the three stainings (Fig. 3d), CD146 staining (in blue) appears co-localised with the red staining (MSCs), indicating that only cells from the MSC fraction expressing CD146 were enrolled in the cellular network. The same observation was made for the MM cells (data not shown).

\section{D co-culture}

Based on the results of the Matrigel ${ }^{\mathrm{TM}}$ assays, cells were seeded in 3D scaffolds in different conditions. MSCs were cultured alone, or in association with either EPCs or HUVECs in the ratio of $75 \%: 25 \%$ and $50 \%: 50 \%$, respectively (MSC-EPC, MSC-HUVEC). As different cell types have different requirements, and 3D co-cultures are long-term experiments, four media were tested (see Materials \& Methods section). Each condition was seeded with cells from 3 donors in duplicate.

\section{Cell organisation within the scaffolds}

After 7 days of culture, the scaffolds were processed for cryosectioning. Ten $\mu \mathrm{m}$ sections were made and stained with toluidine blue.

As seen in Fig. 4 (a-h), both media containing dexamethasone (Medium 3 and Medium 4) showed a well-established and more "stroma-like" extracellular matrix, as compared to the media conditions without (data not shown). Figures $4 \mathrm{a}$ and $\mathrm{b}$ show the scaffolds that were seeded with MSCs only, while Figs. $4 \mathrm{c}$ to f show the MSCs cultured with HUVECs (c-d), or with EPCs (e-f). When cells were co-cultured in a $75 \%: 25 \%$ ratio (c-f), circular structures with intercellular lumen could be observed (white arrows). These cellular rearrangements became slightly more abundant and organised when the percentage of EPCs seeded was increased to $50 \%$ (g-h). When MSCs were cultured alone (Figs. $4 \mathrm{a}-\mathrm{b}$ ), such structures were significantly less abundant. When scaffolds containing 

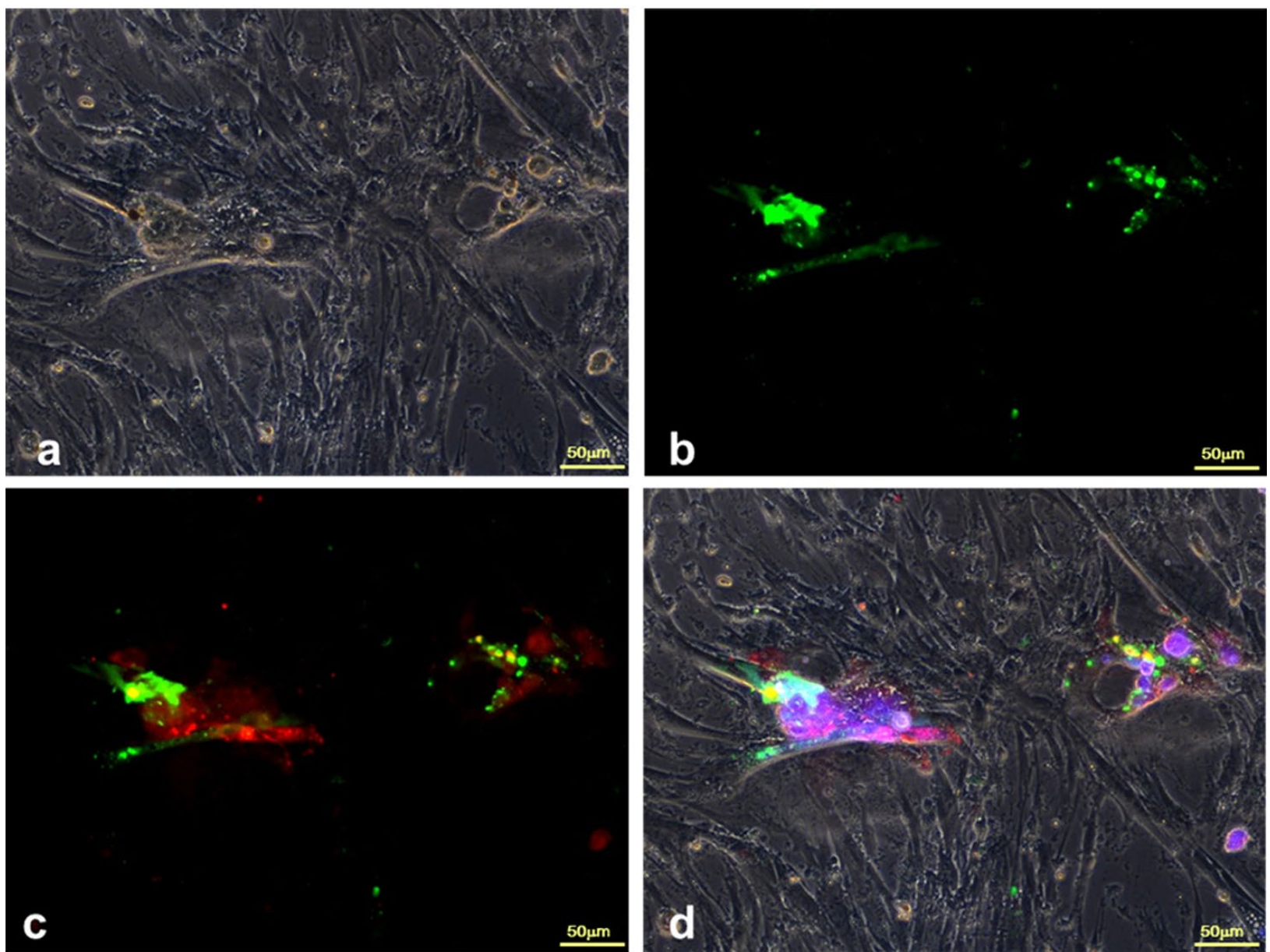

Fig. 3. Characterisation of the cells participating to the cellular network. Matrigel ${ }^{\mathrm{TM}}$ was co-seeded with $50 \%$ of pre-labelled MM cells (red) and $50 \%$ of pre-stained EPCs (green). Samples were cultured for 7 days in Medium 3, and then stained using a CD146-specific antibody (blue). After 7 days of culture in Medium 3, the cells proliferated forming a confluent monolayer and tubular structures could only be observed in some places. (a) General view of the co-culture (contrast phase), (b, c, d) epifluorescence observation, (b) EPCs, (c) EPCs (green) and MMs (red), (d): merged picture showing EPCs (green) and MM expressing CD146 (co-localisation of red and blue staining). (Representative pictures of 3 separate experiments seeded in triplicate).

co-cultures or a single cell type were cultured in Medium 1 or Medium 2, reorganisation into circular structures was never observed (data not shown). Therefore, subsequent experiments were conducted in Medium 3 and Medium 4.

To further investigate the three dimensional distribution of these cells, sequential sectioning of the same scaffolds was performed. Circular structures were found at similar locations on serial sections (Fig. 5). Cryosections separated from each other by about $80 \mu \mathrm{m}$ were stained with toluidine blue (Figs. 5 a,b). The same lumen could be followed over sections (dashed arrow). When sections were stained with the endothelial cell marker antibody PECAM-1 (Figs. 5c-d), the circular structures were well distinguished (section $\mathrm{c}$ ), and still present at a distance of more than $100 \mu \mathrm{m}$ (dashed arrows, section d). This suggests that the assemblies previously described as circular structures are in fact cross-sections of luminal tubular structures present within the 3D scaffolds. These were always identified in co-culture conditions, but only in the presence of dexamethasone (media 3 and 4). When MSCs were cultured on their own, such structures could never be observed, independent from the culture medium used. Therefore, all subsequent experiments were performed using Medium 3, and scaffolds seeded with either $100 \%$ MSCs, or a $50 \%: 50 \%$ ratio of MSC:HUVEC or MSC:EPC.

\section{Characterisation of the cells involved in the tubular structures}

Cells involved in the tubular structures were further characterised by immunohistochemistry (Fig. 6). As shown by the DAPI nuclei staining (in blue), cells were well distributed across the scaffolds. Using a PECAM-1-specific antibody (Figs. 6a-c), endothelial cells were detected only in co-culture conditions (b-c) and exclusively on cells participating in the tubular arrangements (white arrow heads). The same staining localisation could be observed using a vWF-specific antibody (Figs. 6d-f), where most of the positive staining was in the cells participating in the tubular-like structures. In the scaffolds seeded with only MSCs (Figs. 6a and d), no staining for PECAM-1 or vWF could be detected. 


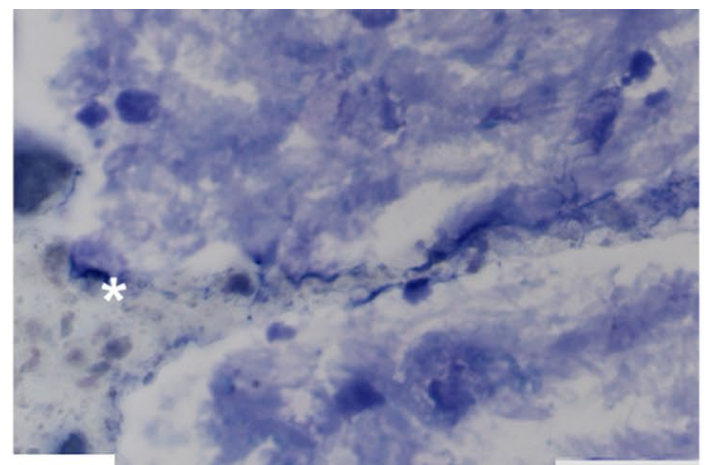

a
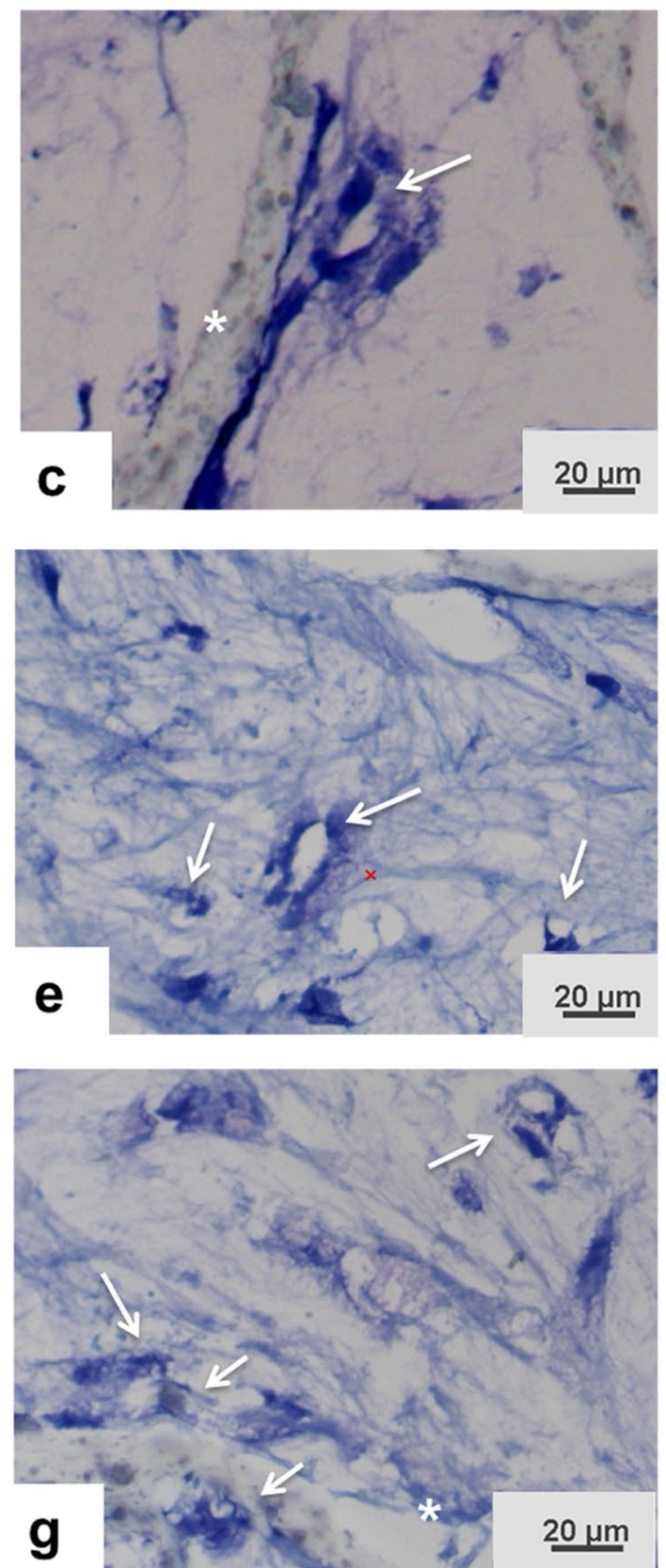
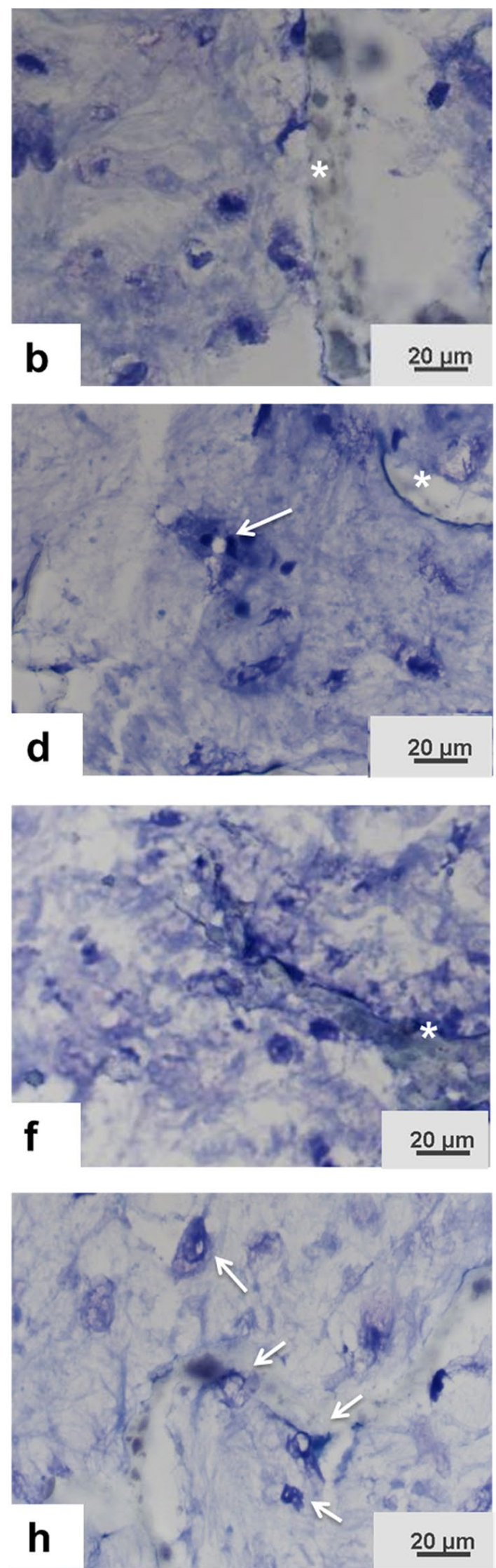

Fig. 4. Cell re-organisation in 3D co-cultures. Two scaffolds per condition and per donor were seeded and incubated for 7 days, then cryosectioned and stained with toluidine blue. Cells were seeded in PU-HA scaffolds in the presence of PRP and cultured in Medium 3 (a, c, d, e) or Medium 4 (b, d, f, g). MSCs seeded on their own (a and b), MSCs cultured with HUVECs in a $75 \%: 25 \%$ ratio (c and d). MSCs cultured with EPCs in a $75 \%: 25 \%$ ratio (e and f). MSCs co-seeded with EPCs in a $50 \%: 50 \%$ ratio ( $\mathbf{g}$ and $\mathbf{h}$ ). White stars show PU-HA material and cellular re-organisation within the matrix, observed exclusively in co-culture cases (white arrows). 

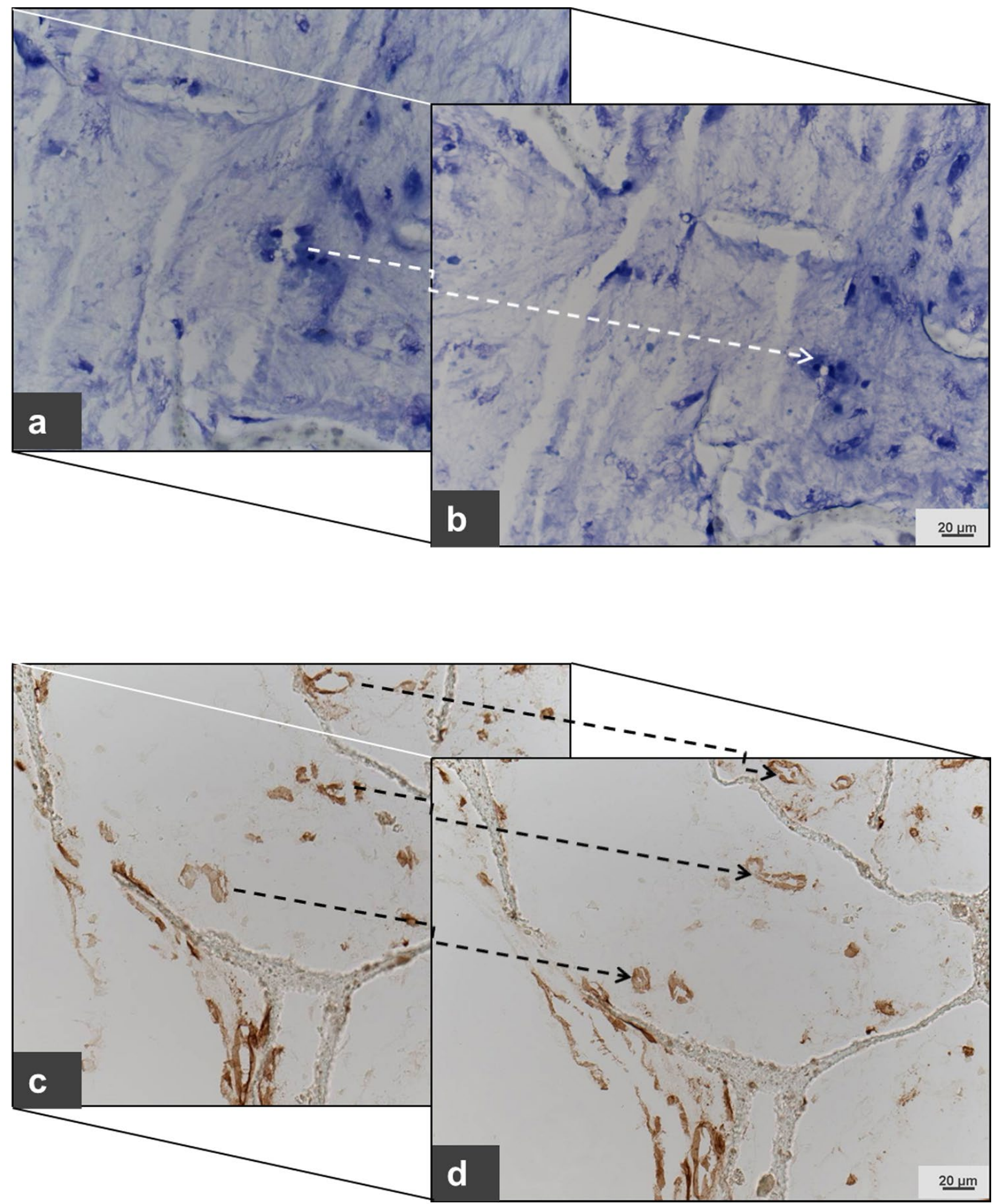

Fig. 5. Sequential sectioning of PU-HA scaffolds ( 2 scaffolds per donor). Cryosections (10 $\mu \mathrm{m})$ were stained with basic toluidine blue staining (a, b) or using PECAM-1-specific antibody (c, d) after 7 days of MSC and HUVEC co-culture (50\% each). The sections stained with toluidine blue (a, b) or with PECAM-1 (c and d) are the first and the last one of a sequence of 8 sections respectively, representing a distance of $80 \mu \mathrm{m}$ in between (a) and (b) and around $100 \mu \mathrm{m}$ between (c) and (d). In both stainings, cellular reorganisation could be followed over the two represented sections (dashed arrows), indicating that these PECAM-1-positive structures represent an inter-tubular lumen extended over a few hundred $\mu \mathrm{m}$. 

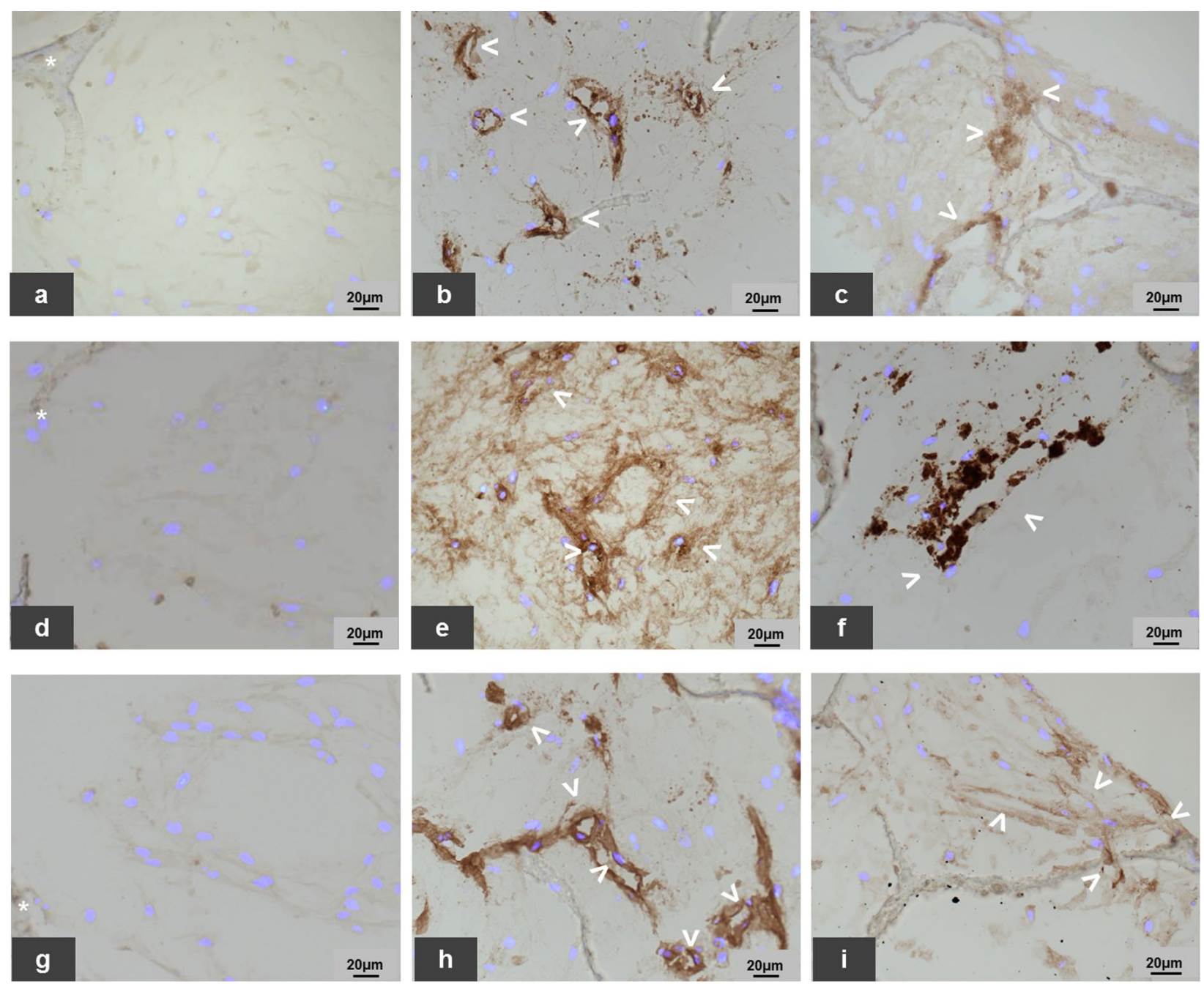

Fig. 6. Immunohistochemical staining of the 3D constructs after 7 days of culture in Medium 3. MSCs were cultured either alone (a, d, g), with $50 \%$ HUVECs $(\mathbf{b}, \mathbf{e}, \mathbf{h})$ or with $50 \%$ EPCs $(\mathbf{c}, \mathbf{f}, \mathbf{i})$. When MSCs were co-cultured with HUVECs or EPCs, the presence of tubular structures positive for PECAM-1 (b, c), vWF (e, f) and CD146 (h, i) could be detected (white arrow heads), while none could be detected for the MSCs-only condition (a, d, g). The overall cell distribution was detected using DAPI nuclear staining (in blue).

Likewise, CD146 (detected in mature endothelial cells and pericytes) was not detected when MSCs were cultured alone (Fig. 6g). However, in co-cultures, CD146 staining was concentrated mainly at the periphery of the tubular assemblies (Figs. 6h-i), as with the other endothelial cell markers.

\section{Further characterisation of pericytes}

As CD146 can be detected on different cell types (e.g., mature endothelial cells, mural cells), we performed additional immunostainings using NG2 and $\alpha$ SMA specific antibodies. As previously mentioned, cryosections were collected sequentially (Fig. 7), and the overall distribution of cells in the scaffolds was detected using DAPI nuclear staining. Positive labelling at the level of the tubular-like structures was obtained for each of the 3 markers on 3 consecutive sections, but only in co-cultured scaffolds (MSC/EPC, MSC/HUVEC) (Figs. 7a-f, white circles). Unstained cells could be detected by counterstaining with
DAPI (representative pictures of scaffolds seeded with cells from 3 different donors).

\section{Quantification of mature pre-vascular structures}

The number of tubular-like structures was quantified from the toluidine blue staining. As shown in Fig. 8a, a significantly higher number of these pre-vascularisation features were found in the scaffolds seeded with MSCs together with $25 \%$ EPCs, as compared to MSCs alone. Those features increased even more when $50 \%$ EPCs were used. When stained with mature endothelial cell markers (PECAM-1 and vWF) and a pericyte marker (CD146), a clear prevalence of "mature" tubular structures was observed in the constructs containing EPCs, as compared to those seeded with MSCs alone (Fig. 8b). These luminal structures were more mature (PECAM-1, vWF and CD146 triple positive) and abundant (around $60 \%$ more) in MSC-HUVEC constructs (mature endothelial cells) when compared to MSC-EPC co-cultures (data not shown). 

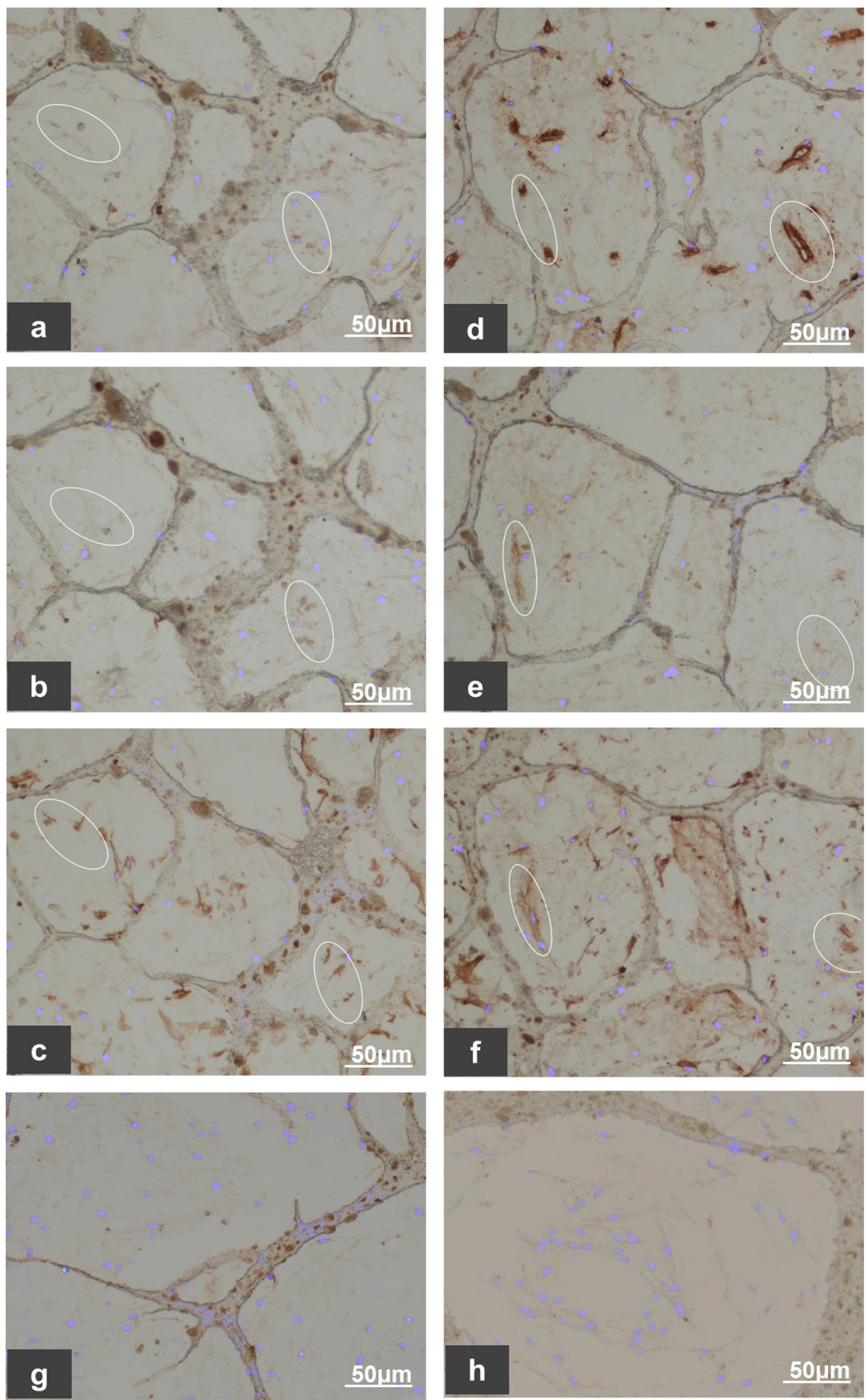

Fig. 7. Pericyte participation in the tubular structures was shown by immunohistochemistry performed on successive cryosections of the constructs, using CD146 (a, d), NG2 (b, e) and $\alpha \operatorname{SMA}(\mathbf{c}, \mathbf{f})$ antibodies. In scaffolds seeded with MSC/ EPC (50:50 ratio) (a, b, c), a positive staining could be observed for the 3 pericyte markers, at the same location over the sections (white circles). Similarly, scaffolds seeded with MSC/HUVEC showed co-staining for pericyte markers (d, e, f, white circles), indicating that these tubular structures also involved pericytes. Negative controls (primary antibody omitted) are shown in $\mathbf{g}$ and $\mathbf{h}$, and the overall cell repartition is visible due to DAPI counter-staining. Consecutive sections were around $100 \mu \mathrm{m}$ from each other (Scale bar $=50 \mu \mathrm{m})$. 

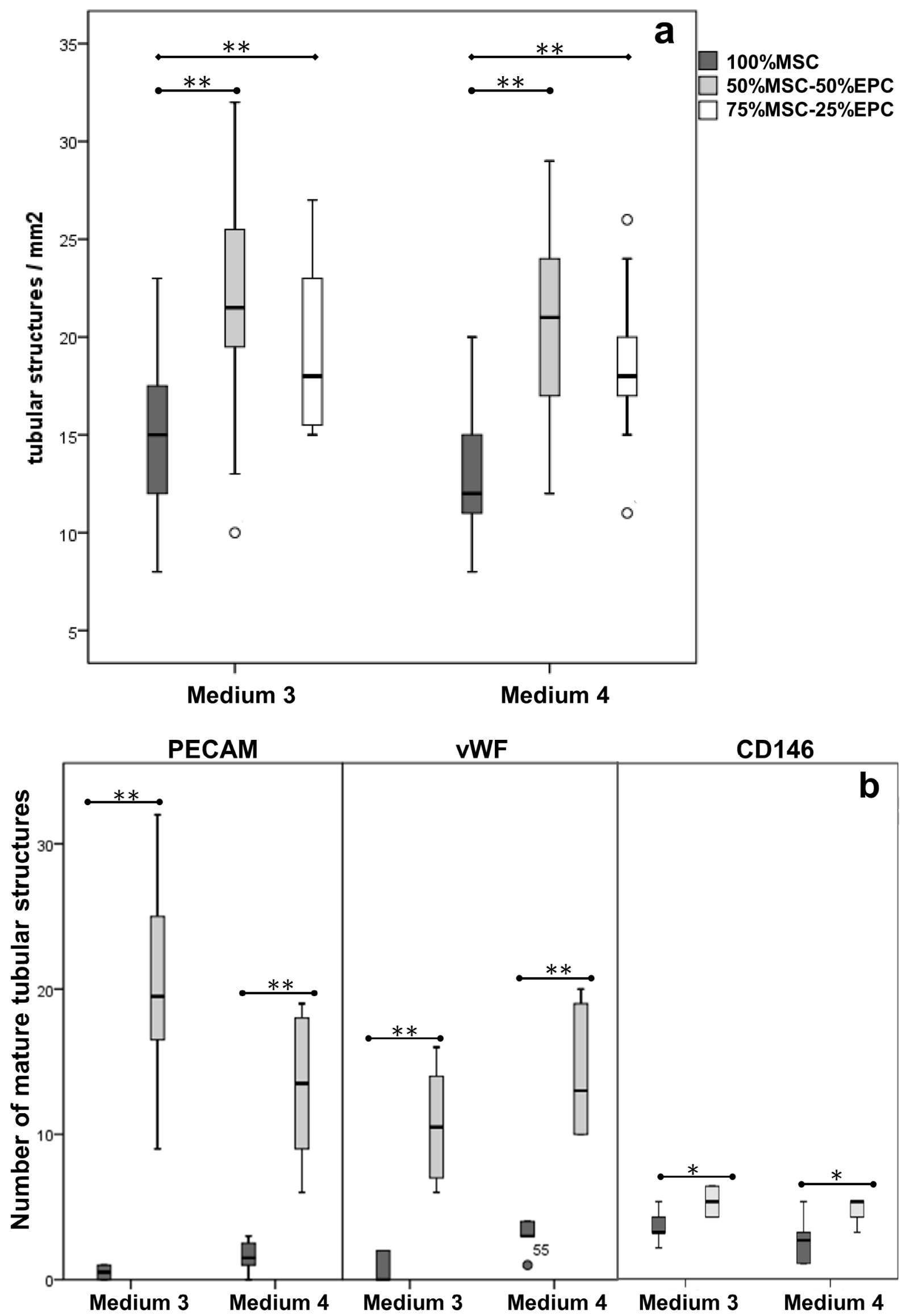

Fig. 8. Quantification of tubular-like structures. The presence of cell reorganisation was manually counted by 2 different observers. Five fields of view were counted per section from each sample ( 2 sections per sample, 2 samples per donor). Counting was performed on toluidine blue stained sections (a) or on sections stained for PECAM-1, vWF and CD146 (b). 


\section{Discussion}

In the context of large bone defects, tissue-engineering approaches have become the most promising alternative to the actual gold standard, namely autologous bone graft. However, the microvasculature network required for the in vivo survival, maintenance and function of such constructs is still a problem. Neovascularisation is a time-consuming process, as blood vessels grow in from surrounding tissues by angiogenesis (Laschke and Menger, 2012). This multistep process involves the ability of endothelial cells to sprout out from pre-existing microvessels and extend toward the implanted tissue. In most large defect cases, this physiological growth is too slow (about $5 \mu \mathrm{m} / \mathrm{h}$ ) to ensure perfusion, and consequently only the periphery of the implant is usually vascularised. Therefore, the presence of pre-vascular networks inside tissue-engineered constructs is essential for getting a faster blood supply through the implant.

The aim of the present study was to investigate the ability of EPCs co-cultured with MSCs to develop a precapillary network within 3D PU scaffolds for bone tissue engineering applications. In addition to optimising the two cell populations' association, we also describe an improved 3D culture environment for both EPCs and MSCs. When cultured in vitro and in the presence of angiogenic factors, endothelial cells from capillary origin have shown the ability to spontaneously form luminal microcapillary-like networks in vitro (Folkman and Haudenschild, 1980). Some other studies showed the beneficial effect of co-culturing mature endothelial cells (microvascular or HUVEC) with other cells types (fibroblast, myofibroblast, MSC) (Sato et al., 1987; Berthod et al., 2006; Tsigkou et al., 2010). Those cells serve as mural cells, and secrete an extracellular matrix necessary for the new vessel stabilisation (Kubota et al., 1988; Hoying et al., 1996).

Here, we show that endothelial progenitor cells (EPC) isolated from human bone marrow samples are able to rapidly form cellular networks when cultured on basement membrane protein coatings (Growth factor reduced Matrigel $\left.^{\mathrm{TM}}\right)$. In contrast, when cultured on the same coatings, neither MSCs nor EPC-depleted MSC (MM) fractions developed such cellular complexes. However, when EPCs were reintroduced to those cell populations, a rapid and well-structured cellular network was clearly observed involving both EPCs and cells from the MSC fraction. Of particular interest, the same was observed when EPCs were added to the MM cell fraction (EPC-depleted). Previous investigations on neovascular scaffolding (Maier et al., 2010; Killingsworth and $\mathrm{Wu}, 2011)$ revealed the affiliation of CD146-positive pericytes as an important part of the neovascular structure. This is in line with $\mathrm{Au}$ et al. (Au et al., 2008) who described the contribution of MSCs to the overall stability of newly formed capillaries as providing the structure with perivascular cells. It was also shown that MSCs and pericytes share similar gene setups, indicating a close relationship in terms of differentiation patterns (Covas et al., 2008; Crisan et al., 2008; Caplan and Correa, 2011; Feng et al., 2011). In our study using a CD146-specific antibody, we first detected positive staining after 1 week of co-culture, especially in the cells from the MSC or MM populations participating toward those networks. Thus, the differentiation of the MSC/MM towards CD146-expressing cells results from the direct cell-cell interaction between mesenchymal stem cells and either EPCs or HUVECs. When seeded in 3D polyurethane scaffolds, MSC-EPC co-cultures clearly showed the presence of cells reorganising into luminal tubular structures already after 7 days of incubation in media containing both angiogenic and osteogenic factors (Medium 3 and Medium 4). These capillary-like assemblies were positive not only for endothelial cell markers like PECAM-1 and vWF, but also for CD146, commonly expressed by pericytes. To date, pericytes (mural cells and/or adventitial cells, but different from EPCs, endothelial cells and smooth muscle cells) are still poorly characterised (Sims, 2000; Bondjers et al., 2006). Although NG2, $\alpha$ SMA and CD146 have been shown to be present on cells associated with blood vessels (Nehls and Drenckhahn, 1991; Schlingemann et al., 1991; Ozerdem et al., 2005; Bondjers et al., 2006), none of these markers are exclusive for pericytes. However, the combination of the three tends to confirm the pericyte phenotype. As we performed some immunostaining using antibodies specific to NG2 and $\alpha \mathrm{SMA}$, we observed not only some positive signal at the periphery of the tubular structures, but in other areas, due to the fact that those markers can be expressed in various cell types. Of particular interest was our sequential sectioning of scaffolds in which we could identify areas where each of the three antibodies were detected, and always in association with tubular structures. This was more obvious when mature endothelial cells (HUVECs) were used in the constructs as compared to the scaffolds containing endothelial progenitor cells (less differentiated than HUVECs). MSCs cultured on their own showed their incapacity in forming pre-vascular networks, confirming previous observations by $\mathrm{Au}$ et al. (Au et al., 2008). When $25 \%$ of EPCs were added to the MSCs, a fast (7 days in culture) and clear formation of stabilised tubular structures was observed, involving both vWF-CD31 double-positive cells and pericyte-like cells. The number of these structures increased slightly when a higher EPCs percentage was added $(50 \%)$. When EPCs were seeded alone, no pre-vascular network could be observed in 3D, indicating a major role of MSCs in the differentiation of EPCs towards a more mature endothelial cell phenotype able to form stable a pre-vascular network.

Although the direct mechanisms of tubular-like structure formation in co-culture of MSCs and EPCs are still unknown, it has been shown that mature endothelial cells and osteoblasts affect proliferation, as well as differentiation of each other. Growth factors such as BMP2 and IGF released by endothelial cells affect osteoblast proliferation and differentiation (Bouletreau et al., 2002; Kaigler et al., 2003; Huang et al., 2005). In return, osteoblasts are able to increase endothelial cell viability, proliferation and angiogenesis, by releasing high levels of VEGF (Deckers et al., 2002; Kaigler et al., 2003). In the absence of MSCs, we observed a decreased number of EPCs and of HUVECs after 7 days in 3D culture (data not shown), a phenomenon also described by others (Hofmann et al., 2008). Endothelial cells are known to die rapidly 
if attachment and spreading are impaired (Unger et al., 2007). In our case, microvessel-like structures could only be observed when dexamethasone, known to stimulate in vitro osteogenic differentiation and extracellular matrix production of MSC (Leboy et al., 1991), was added to the culture medium (Medium 3 and Medium 4). Several studies showed the positive effect of growth factors released by PRP on the proliferation and differentiation of osteoblasts and endothelial cells (Lucarelli et al., 2005; Lev et al., 2006; Lin et al., 2006; Roussy et al., 2007; Verrier et al., 2010; Lippross et al., 2011). It has also been described that endothelial cells in co-culture can attach to extracellular matrix proteins produced by osteoblasts or directly to osteoblasts (Stein et al., 1990; Unger et al., 2007), while proliferating MSCs co-cultured with HUVECs do not support the neovascularisation process (Tsigkou et al., 2010). Taken together, this confirms the dual function of the MSCs in the production of neovascular networks in 3D constructs. On one hand, they support the neovascularisation process as they differentiate toward osteoblast-like cells, and on the other hand, they participate in the stabilisation of newly formed capillaries as perivascular cells.

\section{Conclusion}

In conclusion, we showed the potent effect Endothelial Progenitor Cells in promoting in vitro pre-vascularisation within 3D scaffolds when co-cultured with Mesenchymal Stem Cells. MSCs were shown to play at least two distinct roles in this process. The presence of MSCs in osteogenic medium supports the differentiation of EPCs towards a more mature endothelial cell phenotype. In addition, as proven by the detection of pericyte markers on MSCs associated with the newly formed tubular structures, they also participate in the overall stabilisation of the vessels. This pre-vascular network could be seen as early as 7 days, when the scaffolds were cultured in the presence of both angiogenic and osteogenic factors in the medium (media 3 and 4). The presence of such pre-capillary networks throughout 3D scaffolds prior to implantation is of real interest, as anastomosis with pre-existing luminal structures is a much faster process than capillary invasion from surrounding tissues. Our next step is to investigate the functionality of these pre-vascularised constructs when implanted in vivo.

\section{Acknowledgements}

The authors wish to thank S. Egli and N. Goudsouzian for their precious technical assistance. We also thank Dr D. Eglin and M. Glarner for the preparation of the polyurethane scaffolds.

\section{References}

Asahara T, Murohara T, Sullivan A, Silver M, van der Zee R, Li T, Witzenbichler B, Schatteman G, Isner JM
(1997) Isolation of putative progenitor endothelial cells for angiogenesis. Science 275: 964-967.

Au P, Tam J, Fukumura D, Jain RK (2008) Bone marrow-derived mesenchymal stem cells facilitate engineering of long-lasting functional vasculature. Blood 111: 4551-4558.

Berthod F, Germain L, Tremblay N, Auger FA (2006) Extracellular matrix deposition by fibroblasts is necessary to promote capillary-like tube formation in vitro. J Cell Physiol 207: 491-498.

Bondjers C, He L, Takemoto M, Norlin J, Asker N, Hellstrom M, Lindahl P, Betsholtz C (2006) Microarray analysis of blood microvessels from PDGF-B and PDGFRbeta mutant mice identifies novel markers for brain pericytes. FASEB J 20: 1703-1705.

Bouletreau PJ, Warren SM, Spector JA, Peled ZM, Gerrets RP, Greenwald JA, Longaker MT (2002) Hypoxia and VEGF up-regulate BMP-2 mRNA and protein expression in microvascular endothelial cells: implications for fracture healing. Plast Reconstr Surg 109: 2384-2397.

Caplan AI, Correa D (2011) PDGF in bone formation and regeneration: new insights into a novel mechanism involving MSCs. J Orthop Res 29: 1795-1803.

Capobianco S, Chennamaneni V, Mittal M, Zhang N, Zhang C (2010) Endothelial progenitor cells as factors in neovascularization and endothelial repair. World J Cardiol 2: 411-420.

Carano RA, Filvaroff EH (2003) Angiogenesis and bone repair. Drug Discov Today 8: 980-989.

Covas DT, Panepucci RA, Fontes AM, Silva WA Jr, Orellana MD, Freitas MC, Neder L, Santos AR, Peres LC, Jamur MC, Zago MA (2008) Multipotent mesenchymal stromal cells obtained from diverse human tissues share functional properties and gene-expression profile with CD146+ perivascular cells and fibroblasts. Exp Hematol 36: $642-654$.

Crisan M, Yap S, Casteilla L, Chen CW, Corselli M, Park TS, Andriolo G, Sun B, Zheng B, Zhang L, Norotte C, Teng PN, Traas J, Schugar R, Deasy BM, Badylak S, Buhring HJ, Giacobino JP, Lazzari L, Huard J, Peault B (2008) A perivascular origin for mesenchymal stem cells in multiple human organs. Cell Stem Cell 3: 301-313.

Deckers MM, Van Bezooijen RL, Van der Horst G, Hoogendam J, Van Der Bent C, Papapoulos SE, Lowik CW (2002) Bone morphogenetic proteins stimulate angiogenesis through osteoblast-derived vascular endothelial growth factor A. Endocrinology 143: 15451553.

Deleu J, Trueta J (1965) Vascularisation of bone grafts in the anterior chamber of the eye. J Bone Joint Surg Br 47: 319-329.

Feng J, Mantesso A, De BC, Nishiyama A, Sharpe PT (2011) Dual origin of mesenchymal stem cells contributing to organ growth and repair. Proc Natl Acad Sci U S A 108: 6503-6508.

Folkman J, Haudenschild C (1980) Angiogenesis in vitro. Nature 288: 551-556.

Fuchs S, Ghanaati S, Orth C, Barbeck M, Kolbe M, Hofmann A, Eblenkamp M, Gomes M, Reis RL, Kirkpatrick CJ (2009) Contribution of outgrowth endothelial cells from human peripheral blood on in vivo 
vascularization of bone tissue engineered constructs based on starch polycaprolactone scaffolds. Biomaterials 30: 526-534.

Fuchs S, Hofmann A, Kirkpatrick CJ (2007) Microvessel-like structures from outgrowth endothelial cells from human peripheral blood in 2-dimensional and 3-dimensional co-cultures with osteoblastic lineage cells. Tissue Eng 13: 2577-2588.

Gehling UM, Ergun S, Schumacher U, Wagener C, Pantel K, Otte M, Schuch G, Schafhausen P, Mende T, Kilic N, Kluge K, Schafer B, Hossfeld DK, Fiedler W (2000) In vitro differentiation of endothelial cells from AC133-positive progenitor cells. Blood 95: 3106-3112.

Gorna K, Gogolewski S (2000) Novel biodegradable polyurethanes for medical application. In: Synthetic bioabsorbable polymers for implants, ASTM STP 1396 (Agrawal CM, Parr JE, Lin ST, eds). American Society for Testing and Materials, West Conshohocken, PA, 39-57.

Gorna K, Gogolewski S (2003) Preparation, degradation, and calcification of biodegradable polyurethane foams for bone graft substitutes. J Biomed Mater Res A 67: 813-827.

Gorna K, Gogolewski S (2006) Biodegradable porous polyurethane scaffolds for tissue repair and regeneration. J Biomed Mater Res A 79: 128-138.

Grellier M, Bordenave L, Amedee J (2009) Cell-tocell communication between osteogenic and endothelial lineages: implications for tissue engineering. Trends Biotechnol 27: 562-571.

Hofmann A, Ritz U, Verrier S, Eglin D, Alini M, Fuchs S, Kirkpatrick CJ, Rommens PM (2008) The effect of human osteoblasts on proliferation and neo-vessel formation of human umbilical vein endothelial cells in a long-term 3D co-culture on polyurethane scaffolds. Biomaterials 29: 4217-4226.

Hoying JB, Boswell CA, Williams SK (1996) Angiogenic potential of microvessel fragments established in three-dimensional collagen gels. In Vitro Cell Dev Biol Anim 32: 409-419.

Hristov M, Erl W, Weber PC (2003) Endothelial progenitor cells: mobilization, differentiation, and homing. Arterioscler Thromb Vasc Biol 23: 1185-1189.

Hristov M, Weber C (2004) Endothelial progenitor cells: characterization, pathophysiology, and possible clinical relevance. J Cell Mol Med 8: 498-508.

Huang YC, Kaigler D, Rice KG, Krebsbach PH, Mooney DJ (2005) Combined angiogenic and osteogenic factor delivery enhances bone marrow stromal cell-driven bone regeneration. J Bone Miner Res 20: 848-857.

Johnson EO, Troupis T, Soucacos PN (2011) Tissueengineered vascularized bone grafts: Basic science and clinical relevance to trauma and reconstructive microsurgery. Microsurgery 31: 176-182.

Jones AR, Clark CC, Brighton CT (1995) Microvessel endothelial cells and pericytes increase proliferation and repress osteoblast phenotypic markers in rat calvarial bone cell cultures. J Orthop Res 13: 553-561.

Kaigler D, Krebsbach PH, Polverini PJ, Mooney DJ (2003) Role of vascular endothelial growth factor in bone marrow stromal cell modulation of endothelial cells. Tissue Eng 9: 95-103.
Killingsworth MC, Wu X (2011) Vascular pericyte density and angiogenesis associated with adenocarcinoma of the prostate. Pathobiology 78: 24-34.

Kubota Y, Kleinman HK, Martin GR, Lawley TJ (1988) Role of laminin and basement membrane in the morphological differentiation of human endothelial cells into capillary-like structures. J Cell Biol 107: 1589-1598.

Laschke MW, Menger MD (2012) Vascularization in tissue engineering: angiogenesis versus inosculation. Eur Surg Res 48: 85-92.

Laschke MW, Rucker M, Jensen G, Carvalho C, Mulhaupt R, Gellrich NC, Menger MD (2008) Improvement of vascularization of PLGA scaffolds by inosculation of in situ-preformed functional blood vessels with the host microvasculature. Ann Surg 248: 939-948.

Laschke MW, Strohe A, Menger MD, Alini M, Eglin D (2010) In vitro and in vivo evaluation of a novel nanosize hydroxyapatite particles/poly(ester-urethane) composite scaffold for bone tissue engineering. Acta Biomater 6: 2020-2027.

Leboy PS, Beresford JN, Devlin C, Owen ME (1991) Dexamethasone induction of osteoblast mRNAs in rat marrow stromal cell cultures. J Cell Physiol 146: 370-378.

Lev EI, Estrov Z, Aboulfatova K, Harris D, Granada JF, Alviar C, Kleiman NS, Dong JF (2006) Potential role of activated platelets in homing of human endothelial progenitor cells to subendothelial matrix. Thromb Haemost 96: 498-504.

Lian JB, Stein GS (1995) Development of the osteoblast phenotype: molecular mechanisms mediating osteoblast growth and differentiation. Iowa Orthop J 15: 118-140.

Lin SS, Landesberg R, Chin HS, Lin J, Eisig SB, Lu $\mathrm{HH}$ (2006) Controlled release of PRP-derived growth factors promotes osteogenic differentiation of human mesenchymal stem cells. Conf Proc IEEE Eng Med Biol Soc 1: 4358-4361.

Lippross S, Loibl M, Hoppe S, Meury T, Benneker L, Alini M, Verrier S (2011) Platelet released growth factors boost expansion of bone marrow derived CD34(+) and CD133(+) endothelial progenitor cells for autologous grafting. Platelets 22: 422-432.

Lucarelli E, Fini M, Beccheroni A, Giavaresi G, Di Bella C, Aldini NN, Guzzardella G, Martini L, Cenacchi A, Di Maggio N, Sangiorgi L, Fornasari PM, Mercuri M, Giardino R, Donati D (2005) Stromal stem cells and platelet-rich plasma improve bone allograft integration. Clin Orthop Relat Res 435: 62-68.

Maier CL, Shepherd BR, Yi T, Pober JS (2010) Explant outgrowth, propagation and characterization of human pericytes. Microcirculation 17: 367-380.

Mandracchia VJ, Nelson SC, Barp EA (2001) Current concepts of bone healing. Clin Podiatr Med Surg 18: 55-77.

Martin I, Muraglia A, Campanile G, Cancedda R, Quarto R (1997) Fibroblast growth factor-2 supports ex vivo expansion and maintenance of osteogenic precursors from human bone marrow. Endocrinology 138: 4456-4462.

Meury T, Verrier S, Alini M (2006) Human endothelial cells inhibit BMSC differentiation into mature osteoblasts in vitro by interfering with osterix expression. J Cell Biochem 98: 992-1006. 
Nehls V, Drenckhahn D (1991) Heterogeneity of microvascular pericytes for smooth muscle type alphaactin. J Cell Biol 113: 147-154.

Novosel EC, Kleinhans C, Kluger PJ (2011) Vascularization is the key challenge in tissue engineering. Adv Drug Deliv Rev 63: 300-311.

Ozerdem U, Alitalo K, Salven P, Li A (2005) Contribution of bone marrow-derived pericyte precursor cells to corneal vasculogenesis. Invest Ophthalmol Vis Sci 46: 3502-3506.

Rafii S, Lyden D (2003) Therapeutic stem and progenitor cell transplantation for organ vascularization and regeneration. Nat Med 9: 702-712.

Rhinelander FW (1965) Some Aspects of the microcirculation of healing bone. Clin Orthop Relat Res 40: 12-16.

Roussy Y, Bertrand Duchesne MP, Gagnon G (2007) Activation of human platelet-rich plasmas: effect on growth factors release, cell division and in vivo bone formation. Clin Oral Implants Res 18: 639-648.

Salgado AJ, Gomes ME, Coutinho OP, Reis RL (2004) Isolation and osteogenic differentiation of bone-marrow progenitor cells for application in tissue engineering. Methods Mol Biol 238: 123-130.

Santos MI, Unger RE, Sousa RA, Reis RL, Kirkpatrick CJ (2009) Crosstalk between osteoblasts and endothelial cells co-cultured on a polycaprolactone-starch scaffold and the in vitro development of vascularization. Biomaterials 30: 4407-4415.

Sato N, Sawasaki Y, Senoo A, Fuse Y, Hirano Y, Goto T (1987) Development of capillary networks from rat microvascular fragments in vitro: the role of myofibroblastic cells. Microvasc Res 33: 194-210.

Schlingemann RO, Rietveld FJ, Kwaspen F, Van de Kerkhof PC, De Waal RM, Ruiter DJ (1991) Differential expression of markers for endothelial cells, pericytes, and basal lamina in the microvasculature of tumors and granulation tissue. Am J Pathol 138: 1335-1347.

Sims DE (2000) Diversity within pericytes. Clin Exp Pharmacol Physiol 27: 842-846.

Stein GS, Lian JB, Owen TA (1990) Relationship of cell growth to the regulation of tissue-specific gene expression during osteoblast differentiation. FASEB J 4: 3111-3123.

Street J, Bao M, DeGuzman L, Bunting S, Peale FV Jr, Ferrara N, Steinmetz H, Hoeffel J, Cleland JL, Daugherty A, Van Bruggen N, Redmond HP, Carano RA, Filvaroff EH (2002) Vascular endothelial growth factor stimulates bone repair by promoting angiogenesis and bone turnover. Proc Natl Acad Sci USA 99: 9656-9661.

Tsigkou O, Pomerantseva I, Spencer JA, Redondo PA, Hart AR, O’Doherty E, Lin Y, Friedrich CC, Daheron L, Lin CP, Sundback CA, Vacanti JP, Neville C (2010) Engineered vascularized bone grafts. Proc Natl Acad Sci USA 107: 3311-3316.

Unger RE, Sartoris A, Peters K, Motta A, Migliaresi C, Kunkel M, Bulnheim U, Rychly J, Kirkpatrick CJ (2007) Tissue-like self-assembly in cocultures of endothelial cells and osteoblasts and the formation of microcapillarylike structures on three-dimensional porous biomaterials. Biomaterials 28: 3965-3976.
Verrier S, Meury TR, Kupcsik L, Heini P, Stoll T, Alini M (2010) Platelet-released supernatant induces osteoblastic differentiation of human mesenchymal stem cells: potential role of BMP-2. Eur Cell Mater 20: 403-414.

Villars F, Bordenave L, Bareille R, Amedee J (2000) Effect of human endothelial cells on human bone marrow stromal cell phenotype: role of VEGF? J Cell Biochem 79: 672-685.

Villars F, Guillotin B, Amedee T, Dutoya S, Bordenave L, Bareille R, Amedee J (2002) Effect of HUVEC on human osteoprogenitor cell differentiation needs heterotypic gap junction communication. Am J Physiol Cell Physiol 282: C775.

Wang DS, Miura M, Demura H, Sato K (1997) Anabolic effects of 1,25-dihydroxyvitamin D3 on osteoblasts are enhanced by vascular endothelial growth factor produced by osteoblasts and by growth factors produced by endothelial cells. Endocrinology 138: 2953-2962.

Zammaretti P, Zisch AH (2005) Adult 'endothelial progenitor cells'. Renewing vasculature. Int J Biochem Cell Biol 37: 493-503.

\section{Discussion with Reviewers}

M. Laschke: Regarding the MSC population, did you perform any characterisation?

Authors: In our laboratory, we have about 15 years of experience using MSC isolated this way. Indeed, in several parallel studies and regular test of foetal calf serum batches, we do evaluate the differentiation of these MSC toward chondrogenic and adipogenic phenotypes as well. In order not to over load the present manuscript, the MSC characterisation was not included. Moreover as published by Whitney et al. (2009) (additional reference), to date, there is not real CD marker to characterise MSC, therefore their ability to differentiate into chondrocyte, adipocyte and osteoblast seems to be the most adequate.

M. Laschke: You state that you found vessel-like structures with a lumen in their constructs. How can you be sure that this was a real lumen and not a simple histological artefact? A real lumen would be surrounded by a layer of endothelial cells. Accordingly, I suggest the performing of much more detailed morphological analyses of the vessel-like structures. For instance, this may be achieved by additional electron microscopic imaging.

Authors: Due to the persistence of the lumen over multiple serial sections, we consider that the structures are luminal vessel-like structures. Moreover, PECAM staining really showed the presence of endothelial cells around these structures, supported by the presence of cells showing pericyte markers. We will, however, definitely perform electron microscopy imaging in further studies.

M. Laschke: Proof is missing that the observed tubular vessel-like structures would have any function under in vivo conditions, which, at least for later clinical applications, is the most important question to clarify. Please comment. 
Authors: This point is currently under investigation through an in vivo nude mice sub-cutaneous implantation study.

S. Fuchs: In Fig. 7 you highlighted areas in co-cultures of CD34/MSCs which do not meet the definition of a vascular lumen. In addition, staining for CD146 marks endothelial cells in accordance with CD146 expression by endothelial cells, which are highly abundant in the HUVEC/ MSC culture but nearly absent in CD34/ MSCs.

Authors: We agree that it is difficult to recognise any well-defined structures (e.g., lumen) in the EPC/MSC co-culture scaffolds. The staining presented in Fig. 7 is specific for CD146, NG2 and $\alpha \mathrm{SMA}$. None of these markers is exclusively expressed on pericyte cells, but the combination of them is a strong indication of the pericyte phenotype. HUVEC cells are more mature endothelial cells when compared with EPC. Therefore, they are able to develop more mature luminal structures when co-cultured with MSC (none of such structures were observed when HUVEC were cultured on their own).

S. Fuchs: CD146 is a marker expressed on mature endothelial cells but is also discussed to play a role in the stabilisation of vascular structures and can be expressed in pericyte-like cells. Thus, this marker is very ambiguous to evaluate the origin of pericytes, especially in the experimental settings chosen by the authors. In consequence, the presented data are not completely evident and conclusions regarding the origin of pericytelike cells need further experimental support. This is also accompanied by two major obstacles for this study. On one hand the vascular structures formed by CD34 positive cells under "more stringent angiogenesis conditions" (fibrin/ scaffolding material) seem to be much lower in number and less structured when compared to the HUVECs. Although the direct quantitative comparison of vascular structures of MSC/CD34 cells and MSC/HUVEC cells is missing, this is reflected by the figures. These poorly organised vascular structures shown for CD34/MSC cultures make studies on the grade of vascular stabilisation very difficult. In addition, also more co-stainings for endothelial markers and pericyte markers in morphologically well defined vascular structures in co-cultures of CD34 and MSCs would be needed.

Authors: Indeed, the CD146 marker has been shown to be expressed in mature endothelial cells as well as in other cell types (for instance in pericytes). Therefore we also looked at some other markers (NG2, $\alpha \mathrm{SMA})$, that are not specific to pericytes either, but the combination of them makes our hypothesis that cells participating to the tubular network are pericyte-like cells more convincing.

S. Fuchs: How many CD34 positive cells can be isolated in average from the bone marrow from one donor and do you see a high donor to donor variation for harvesting effectiveness or the biological performance of the cells?

Authors: We indeed observed some donor to donor variations in 22 donors tested. The content of CD34 positive cells tends to decrease with age from about $4 \%$ of the post-Ficoll cell population (at the age of 30 years) towards $0.5 \%$ (for samples from donors above 70 ). However, concerning the biological performance of these cells, we so far never noticed any correlation between the age of the patient and the ability of the cells to grow or form tubular structures.

\section{Additional Reference}

Whitney MJ, Lee A, Ylostalo J, Zeitouni S, Tucker A, Gregory CA (2009) Leukemia inhibitory factor secretion is a predictor and indicator of early progenitor status in adult bone marrow stromal cells. Tissue Eng Part A 15: 33-44. 